\title{
Radial basis function neural networks for modeling growth rates of the basidiomycetes Physisporinus vitreus and Neolentinus lepideus
}

\author{
Mark Schubert • Safer Mourad • Francis Schwarze
}

Received: 1 July 2009 /Revised: 4 August 2009 / Accepted: 4 August 2009 /Published online: 21 August 2009

(C) Springer-Verlag 2009

\begin{abstract}
A radial basis function (RBF) neural network was developed and compared against a quadratic response surface (RS) model for predicting the specific growth rates of the biotechnologically important basidiomycetous fungi, Physisporinus vitreus and Neolentinus lepideus, under three environmental conditions: temperature $\left(10-30{ }^{\circ} \mathrm{C}\right)$, water activity (0.950-9.998), and $\mathrm{pH}$ (4-6). Both the RBF network and polynomial RS model were mathematically evaluated against experimental data using graphical plots and several statistical indices. The evaluation showed that both models gave reasonably good predictions, but the performance of the RBF neural network was superior to that of the classical statistical method for all three data sets used (training, testing, full). Sensitivity analysis revealed that of the three experimental factors the most influential on the growth rate of $P$. vitreus was water activity, followed by temperature and $\mathrm{pH}$ to a lesser extent. In contrast, temperature in particular and then water activity were the key determinants of the development of $N$. lepideus. RBF neural networks could be a powerful technique for
\end{abstract}

Electronic supplementary material The online version of this article (doi:10.1007/s00253-009-2185-3) contains supplementary material, which is available to authorized users.

M. Schubert $(\bowtie) \cdot$ F. Schwarze

Group of Wood Protection and Biotechnology,

Wood Laboratory, EMPA,

Swiss Federal Laboratories for Materials Testing and Research, Lerchenfeldstrasse 5,

9014 St. Gallen, Switzerland

e-mail: mark.schubert@empa.ch

S. Mourad

Media Technology, EMPA, Swiss Federal Laboratories

for Materials Testing and Research,

Lerchenfeldstrasse 5,

9014 St. Gallen, Switzerland modeling fungal growth behavior under certain parameters and an alternative to time-consuming, traditional microbiological techniques.

Keywords Radial basis function neural network . Physisporinus vitreus $\cdot$ Neolentinus lepideus .

Response surface model · Growth rate

\section{Introduction}

Recent investigations have shown that, in combination with conventional histological and analytical methods, wooddecay fungi have many valuable biotechnological applications in the pure and applied wood sciences (Messner et al. 2002; Mai et al. 2004; Schwarze 2008). Alterations in the cell wall structure and/or the distribution of the cell wall constituents are reflected in the plasticity of the wood degradation modes of these fungi (Deflorio et al. 2005; Schwarze 2008). The specificity of their enzymes and the mild conditions under which degradation proceeds make them potentially suitable agents for wood modification, e.g., biopulping and bioremediation (Majcherczyk and Hüttermann 1988; Messner et al. 2002).

The biotechnological process of bioincising is a promising approach to improve the uptake of preservatives and wood-modification substances by refractory wood as a result of selective degradation of bordered pits by the white-rot fungus Physisporinus vitreus (Pers.: Fr.) P. Karst. (Schwarze and Landmesser 2000; Schwarze et al. 2006). Furthermore, because of its exceptional pattern of degradation, $P$. vitreus is successfully used to improve the acoustic properties of the tonewood of Norway spruce wood (Picea abies L.) used for musical instruments by selectively delignifying the secondary walls without affecting the 
middle lamellae, even at advanced stages of degradation (Schwarze et al. 2008; Spycher et al. 2008).

The growth rate (GR) of $P$. vitreus in relation to temperature, water activity $\left(a_{\mathrm{w}}\right)$, and $\mathrm{pH}$ was compared in the present work with that of the brown-rot fungus Neolentinus lepideus ((Fr.: Fr.) Redhead and Ginns, common name $=$ Lentinus lepideus $)$, another important basidiomycete that is used for bioremediation and detoxification of preservative-treated waste wood because of its creosote tolerance and ability to degrade, among other compounds, toxic poly aromatic hydrocarbon compounds (Shuen and Buswell 1992; Cerniglia 1997; Samson et al. 1998; Richter et al. 2003).

Improving the effectiveness of wood modification by minimizing variable performance and optimizing development of the fungi demands an understanding of how abiotic parameters affect their lag phase and GR. The classical method of testing these parameters involves varying the level of each parameter over a certain range, while maintaining the other test variables constant. This strategy is time consuming, requires a large number of experiments, and does not include interactive effects among parameters on the process. In order to overcome these problems, predictions of fungal growth can be obtained using mathematical modeling approaches (Skinner et al. 1994).

Response surface (RS) methodology has been widely used in predictive microbiology for quantitative assessment of the effects of various environmental factors on various ascomycetes (Sparringa et al. 2002; Panagou et al. 2003; Lahlali et al. 2005, 2006; Begoude et al. 2007; Schubert et al. 2009a). The modeling approach has also been used to predict the growth of several bacteria (García-Gimeno et al. 2005; Carrasco et al. 2006; Dong et al. 2007) and to optimize the growth conditions of the alga Nannochloropsis oculata (Spolaore et al. 2006).

As an alternative to the traditional methods of statistical regression, artificial neural networks (ANNs) have recently been developed and found widespread acceptance as datadriven modeling techniques because of their remarkable ability to model highly complex and nonlinear problems in many fields of engineering and science (Basheer and Hajmeer 2000; Hajmeer et al. 2006). ANNs normally have no restriction on the type of relationship between the growth parameters (input patterns) and the desired output, whereas regression-based models require that the order of the model is stated beforehand (Panagou and Kodogiannis 2009). In contrast, ANNs directly explore the knowledge contained in the input-output patterns by adjusting the parameters of the nonlinear ANN topology as the inputoutput patterns are repeatedly presented to the network (Hajmeer et al. 2006). When the system is supervised trained using an appropriate training data set, it can then be used to predict GR for different growth conditions within the initial experimental range (Panagou and Kodogiannis 2009). Radial basis function (RBF) neural networks, a variant of ANNs, were recently used by Panagou et al. (2007) to successfully predict the GR of the ascomycete, Monascus ruber van Tieghem, for the first time.

To the best of our knowledge, RBF neural network methodology has not been used for $P$. vitreus and $N$. lepideus, so the aim of the present work was (1) to develop a RBF neural network to predict GR under different experimental conditions, (2) to compare the predictive accuracy of the RBF approach with RS methodology, and (3) to determine the relative importance of the three parameters (temperature, $a_{\mathrm{w}}$, and $\mathrm{pH}$ ) on the development of $P$. vitreus and $N$. lepideus.

\section{Materials and methods}

\section{Microorganisms}

The cultures of P. vitreus (642) and N. lepideus (340) are maintained and deposited at the EMPA, Materials Science and Technology, Switzerland. The cultures were identified microscopically and additionally the internal transcribed spacer ITS1-5.8S-ITS2 region of the rDNA was amplified and sequenced for $P$. vitreus (EMBL, accession no. FM202494) and $N$. lepideus (EMBL, accession no. FM995531). For the experiments, the initial inoculum was taken from cultures that had been growing on malt extract agar medium (MEA, Oxoid, Darmstadt, Germany) in Petri dishes at $4{ }^{\circ} \mathrm{C}$ for no more than 6 months.

\section{Medium}

The $a_{\mathrm{w}}$ of the basic MEA medium (0.998) was adjusted by adding calculated amounts of nonionic solute (glycerol) to obtain nine different moisture levels $(0.998,0.990,0.982$, 0.974, 0.970, 0.966, 0.958, 0.955, and 0.950) (Dallyn and Fox 1980), measured with an osometer (OM 801, Vogel, Giessen, Germany). The medium was buffered with $0.1 \mathrm{mmol} \mathrm{l}^{-1} \mathrm{NaH}_{2} \mathrm{PO}_{4}$ and the final $\mathrm{pH}$ of the medium was adjusted to 4 or 5 with $1 \mathrm{~mol} \mathrm{l}^{-1} \mathrm{HCL}$, or to 6 with $1 \mathrm{~mol}^{-1} \mathrm{NaOH}$, prior to autoclaving.

Radial growth rate assessment

Using a cork borer, mycelial discs $(9 \mathrm{~mm})$ were removed under sterile conditions from 10-day-old colony cultures of P. vitreus and $N$. lepideus growing on $2 \%$ MEA at $22{ }^{\circ} \mathrm{C}$ and then inoculated at the center of Petri dishes containing the test media. After inoculation, the Petri dishes were sealed in polyethylene bags to prevent water loss and incubated for 20 days at $10,15,20,25$, and $30^{\circ} \mathrm{C}$. A total of 135 full factorial experiments (five temperatures $\times$ nine 
$a_{\mathrm{w}} \times$ three $\left.\mathrm{pH}\right)$ were performed. Three replicates were used for each combination of experimental conditions and each experiment was conducted twice $(n=810)$. The radial growth of each mycelial colony was measured daily in two predetermined directions, without opening the Petri dishes, until the plates were completely colonized. The radial GR $\left(\mathrm{mm} \mathrm{day}{ }^{-1}\right)$ for each $a_{\mathrm{w}}$, temperature, and $\mathrm{pH}$ combination was obtained from linear regression slopes of the temporal growth curves. The lag phase (time required for macroscopically measurable growth) was also assessed for each experimental combination. Combinations of environmental conditions in which no growth occurred were not taken into account for model fitting, resulting in a new database of 75 datasets for $P$. vitreus and 117 datasets for $N$. lepideus. The new database of $P$. vitreus was divided into a training set with a total of 61 data (81\%) and a testing (validation) set with 14 data $(19 \%)$; the same procedure for $N$. lepideus resulted in a training set with a total of 95 data $(81 \%)$ and a testing (validation) set with 22 data (19\%). The testing set was used as the basis for determining the predictive accuracy and was selected randomly, whereas great care was taken to ensure that the training set adequately represented the experimental data of both fungi (Panagou et al. 2007).

\section{Response surface methodology}

The GRs $\left(\mathrm{mm} \mathrm{day}^{-1}\right.$ ) were investigated by analysis of variance. Statistical significance was judged at the level of $P<0.05$. Whenever analysis revealed significant difference, Duncan's multiple range test for separation of means was performed. The mean estimates of GR were then fitted to a quadratic RS model to describe the single and combined effects of temperature, $\mathrm{pH}$, and $a_{\mathrm{w}}$ (Schubert et al. 2009b):

$Y=\beta_{0}+\sum_{i=1}^{k} \beta_{i} x_{i}+\sum_{i=1}^{k} \beta_{i i} x_{i}^{2}+\sum_{i=1}^{k} \sum_{j=i+1}^{k} \beta_{i j} x_{i} x_{j}+\varepsilon$

where $Y=$ response (GR), $\beta_{0}$ coefficient $=$ off-set term called intercept, $x_{i}=$ independent variables related to the factors, $\beta_{i}=$ linear coefficients, $\beta_{i j}=$ second-order interaction coefficients, $\beta_{i i}=$ quadratic coefficients, and $\varepsilon=$ error of the model.

Interactions between factors could appear either as an antagonistic effect (negative coefficient) or a synergistic effect (positive coefficient). Interpretation of the data was based on a positive or negative effect on the response and statistical significance of the coefficients $(P<0.05)$. The higher the absolute value of a linear coefficient $\left(\beta_{x}\right)$, the greater the influence of the corresponding factor.

\section{Radial basis function neural network}

The following brief introduction to RBF neural networks is based on the detailed description and explanation by
Panagou et al. (2007). As illustrated in Fig. 1, the RBFs are embedded in a two-layer feed-forward neural network, with a single hidden layer in which the nodes are Gaussian kernels and a linear output layer. The RBF is represented by the following equation:

$f(x)=\sum_{i=1}^{n r} w_{i} \phi\left(\left\|x-c_{i}\right\|\right)$

where $x=$ input vector, $w_{i}=$ weight of the output layer, $\phi(\cdot)=$ Gaussian kernel, $\|\cdot\|=$ the Euclidean norm, $c_{i}=$ center of the $i$ th kernel, and $n_{r}=$ total number of kernels. The Gaussian $\operatorname{kernel} \varphi(\cdot)$ is defined as:

$\phi\left(\left\|x-c_{i}\right\|\right)=e^{\left(-\frac{\|x-c i\|^{2}}{2 \sigma i^{2}}\right)}$

where $\sigma=$ width of the kernel. In Eq. (3), let $\phi=\exp$ $\left(-0.8326\left\|x-c_{i}\right\| / \mathrm{SPREAD}^{2}\right)$. If $\mathrm{SPREAD}=\left\|x-c_{i}\right\|$, then $\phi=0.5$. Spread determines the width of the area input space to which each neuron in the first layer responds (Demuth et al. 2008). The larger the spread, the smoother the function approximation will be. A too large spread means a lot of neurons will be required to fit a fast changing function. A too small spread means many neurons will be required to fit a smooth function and the network may not generalize well. The key to successful implementation of the network is to find suitable centers for the Gaussian functions, so the appropriate selection of the training data set (supervised) and training algorithm are crucial for the success of the RBF model.

In the following simulations and experiments, training of the RBF neural network was performed by the NEWRB function in Matlab $^{\circledR}$ Software (ver. 7.7.0 MathWorks, R2008a). The final RBF network contained 50 neurons for $P$. vitreus and 75 neurons for $N$. lepideus and one spread parameter for all input variables $(\sigma=1)$ for both fungi. The values of the output weights in the linear layer of the network for both fungi are presented in Table S1 (supplementary material).

\section{Criteria for comparison}

For an appropriate comparison of the robustness and reliability of the RBF neural network and the RS model, both were developed and validated with the same training, testing, and full data sets. To assess the fitting and predictive accuracy of the models, the datasets were mathematically evaluated by calculating the following evaluation criteria: coefficient of determination $\left(R^{2}\right)$ (Box and Draper 1987), root mean squared error (RMSE), standard error of prediction (SEP) (García-Gimeno et al. 2005; Zurera-Cosano et al. 2006), mean relative percentage error (MRPE), mean absolute percentage error (MAPE) (Jeyamkondan et al. 2001), bias factor $\left(B_{f}\right)$, accuracy factor 
Fig. 1 Architecture of the radial basis function neural network

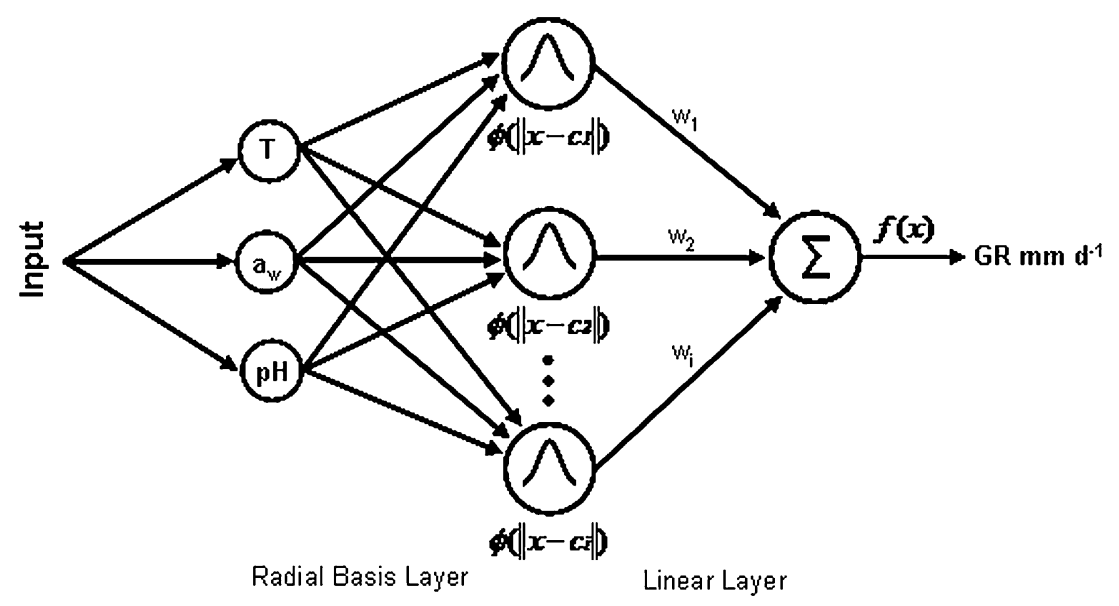

$\left(A_{f}\right)$ (Ross 1996), and the proportion of the relative error (pRE) (Oscar 2005). In addition, a graphical comparison was performed to illustrate the accuracy of the proposed models.

\section{Sensitivity analysis}

The determination of the relative significance of model input parameters, ranking the variables in order of importance, was performed by sensitivity analysis on the trained RBF neural network. The sensitivity of an output parameter, Out Ou $_{1,2, \ldots j}$, to an input parameter, $\operatorname{In}_{i=1,2, \ldots n i}$, was defined as the normalized ratio between variations caused in Out ${ }_{j}$ by variations introduced in $\operatorname{In}_{i}$ (Noble et al. 2000) and is represented by the following equation:

$\mathrm{NS}=\left(\mathrm{dOut}_{j} / \mathrm{dIn}_{i}\right)\left(\operatorname{In}_{i} / \mathrm{Out}_{j}\right)$

\section{Results}

The combined abiotic factors of $a_{\mathrm{w}} \times$ temperature $\times \mathrm{pH}$ tested in this study significantly influenced the mycelial development and growth behavior of the wood-decay fungi $P$. vitreus and $N$. lepideus in different ways. As illustrated in Fig. 2, changing $a_{\mathrm{w}}$ at different steady-state temperatures and $\mathrm{pH}$ levels affected performance by decreasing the GR of both fungi, but particularly of $P$. vitreus. The $a_{\mathrm{w}}$ range in which growth of $P$. vitreus occurred was $0.998-0.970$, whereas within the 20-day incubation period no growth was detected at $a_{\mathrm{w}} \leq 0.966$. For $N$. lepideus, however, growth occurred at $a_{\mathrm{w}} 0.998-0.958$ at all temperatures and $\mathrm{pH}$ levels tested within the incubation period. At $a_{\mathrm{w}}=0.955, N$. lepideus showed detectable growth at temperatures $\geq 15^{\circ} \mathrm{C}$, regardless of $\mathrm{pH}$. The GR of both fungi was higher at $a_{\mathrm{w}}=$ 0.998 and at all temperatures, slightly higher at $\mathrm{pH} 5$ than at 4 or 6 , diminished with decreasing $a_{\mathrm{w}}$ and temperatures and at suboptimal conditions the effect was practically absent.
Both fungi had their growth optima at $\mathrm{pH} 5$ and at the highest $a_{\mathrm{w}}(0.998)$, but at different temperatures. The most supportive temperature for growth was $25^{\circ} \mathrm{C}$ for $P$. vitreus and $30{ }^{\circ} \mathrm{C}$ for $N$. lepideus, provided that the $a_{\mathrm{w}}$ was high enough ( $\geq 0.970$ for $P$. vitreus and $\geq 0.955$ for $N$. lepideus). Growth of both fungi decreased with decreasing temperature, but $P$. vitreus showed detectable growth at all temperatures at $a_{\mathrm{w}} \geq 0.982$, whereas the growth of $N$. lepideus decreased rapidly with decreasing temperatures even at optimal $a_{\mathrm{w}}$ levels (Fig. 2).

Results of the mathematical evaluation of the predictive accuracy of the RBF neural network and statistical RS model are presented in Table 1 and Figs. 3, 4, and 5 for the three data sets (training, testing, full) for $P$. vitreus and $N$. lepideus. As shown in Table 1, both models revealed a good predictive accuracy for $P$. vitreus and $N$. lepideus, but the RBF neural network was able to predict the GR of both fungi, and for all data sets, with greater accuracy than the polynomial model (RS), as inferred by the indices. With the training data sets in particular, the RBF neural network predictions were far superior to those of the RS model for both fungi, as judged by the relevant indices, especially SEP and pRE (Table 1). Figures 3, 4, and 5 show the bias (observed vs. predicted GR mm day ${ }^{-1}$ ), residuals plots, and RE for both models, for all data sets and for P. vitreus and $N$. lepideus, respectively. The bias from the RBF neural network was generally closer to the line of equity $(y=x)$ compared with the RS model for all data sets and for both fungi (Fig. 3). The residual plots revealed that the spread of the residuals of the RBF neural network for both fungi was narrower to zero than for the RS model and additionally, the residuals were distributed symmetrically around zero, indicating no systematic tendency to either the positive or negative side of the graph. The analysis of the RE for all data sets and for both fungi revealed that the RBF neural network was widely within the proposed range from -0.3 fail-safe to 0.15 fail-dangerous under all experimental conditions (optimal-suboptimal), whereas the RS model 
Fig. 2 Effect of water activity and temperature at $\mathrm{pH} 5$ on the radial growth rate of Physisporinus vitreus (a) and Neolentinus lepideus (b). Water activity levels are $0.998(\bullet), 0.990(\bullet), 0.982$ (४), $0.974(\mathbf{\Delta}), 0.970(+), 0.966$ $(*), 0.958(\varangle)$, and $0.955(\triangleright)$. Error bars show standard error (SE) of the estimated parameters. Where the bars are not shown, they are smaller than the symbol size (a)

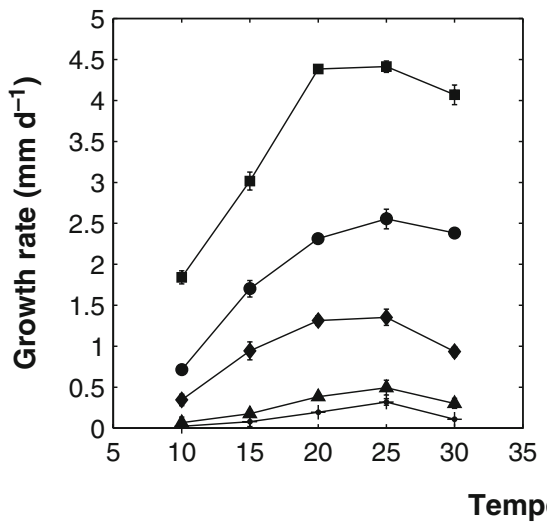

(b)

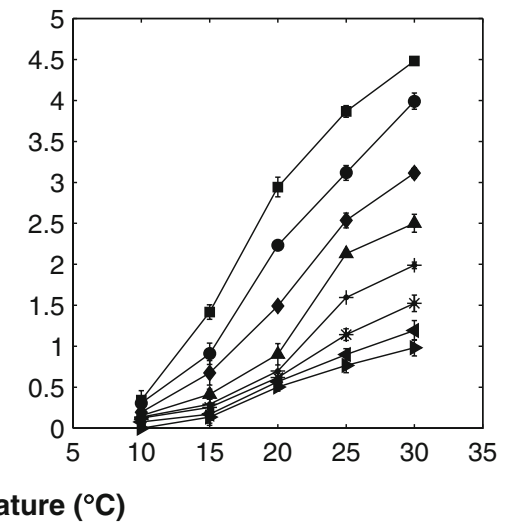

showed good accuracy at supportive growth conditions, but at suboptimal conditions, close to the growth/no growth interface, the values were almost out of the proposed range for all data sets and both fungi (Fig. 5).

The results of multiple regression analysis, which provided estimates of the model coefficients for the training and full data sets of $P$. vitreus and $N$. lepideus, are listed in Table 2. The descending order of the model coefficients of P. vitreus was $a_{\mathrm{w}}\left(\beta_{2}\right)>$ temperature $\left(\beta_{1}\right)>\mathrm{pH}\left(\beta_{3}\right)$, showing that the influence of $a_{\mathrm{w}}$ on growth was greater than that of temperature and $\mathrm{pH}$ for the training and full data sets. In contrast, the regression analysis for $N$. lepideus revealed the highest model coefficient of temperature $\left(\beta_{1}\right)$, followed by $a_{\mathrm{w}}\left(\beta_{2}\right)$ and $\mathrm{pH}\left(\beta_{3}\right)$ for the training and full data sets. The obtained results of the regression analysis were confirmed by sensitivity analysis of the relative significance of model input parameters. Table 3 shows that $a_{\mathrm{w}}$ was the most influential (sensitive) parameter affecting the GR of $P$. vitreus in all data sets (training, testing, full), followed by temperature and $\mathrm{pH}$ to a lesser extent, whereas the growth of $N$. lepideus in all data sets was particularly influenced by temperature, followed by $a_{\mathrm{w}}$ and $\mathrm{pH}$.

\section{Discussion}

Highly efficient modification or detoxification of wood by $P$. vitreus or $N$. lepideus is based on optimal development of the mycelium, including the lag phase, hyphal elongation, and branching. Mycelial growth is greatly influenced by

Table 1 Comparison of the evaluation indices of a radial basis function neural network (RBF) and a statistical model (RSM)

\begin{tabular}{|c|c|c|c|c|c|c|c|}
\hline \multirow[t]{2}{*}{ Statistical index } & \multirow[t]{2}{*}{ Model } & \multicolumn{3}{|c|}{ Data set of $P$. vitreus } & \multicolumn{3}{|c|}{ Data set of $N$. lepideus } \\
\hline & & Training & Testing & Full & Training & Testing & Full \\
\hline \multirow[t]{2}{*}{ Coefficient of determination $\left(R^{2}\right)$} & $\mathrm{RBF}$ & 1.0000 & 0.9959 & 0.9985 & 0.9991 & 0.9947 & 0.9982 \\
\hline & RSM & 0.9910 & 0.9932 & 0.9902 & 0.9899 & 0.9882 & 0.9896 \\
\hline \multirow[t]{2}{*}{ Root mean squared error (RMSE) } & $\mathrm{RBF}$ & 0.0095 & 0.0914 & 0.0738 & 0.0519 & 0.1203 & 0.0717 \\
\hline & RSM & 0.1831 & 0.1384 & 0.1901 & 0.1710 & 0.1692 & 0.1705 \\
\hline \multirow[t]{2}{*}{ Standard error of prediction (SEP\%) } & $\mathrm{RBF}$ & 0.6182 & 9.9923 & 5.4081 & 3.8912 & 10.799 & 5.5619 \\
\hline & RSM & 13.293 & 15.131 & 13.936 & 12.809 & 15.197 & 13.216 \\
\hline \multirow[t]{2}{*}{ Mean relative percentage error (MRPE) } & $\mathrm{RBF}$ & -0.3149 & 2.3616 & 0.4996 & -0.1935 & -2.2686 & -0.5549 \\
\hline & RSM & -8.3817 & -1.9266 & -9.7973 & 1.2234 & 9.6239 & 1.8825 \\
\hline \multirow[t]{2}{*}{ Mean absolute percentage error (MAPE) } & $\mathrm{RBF}$ & 2.8212 & 12.308 & 2.8521 & 3.8258 & 8.8269 & 4.8496 \\
\hline & RSM & 47.781 & 34.705 & 46.132 & 26.228 & 34.798 & 25.576 \\
\hline \multirow[t]{2}{*}{ Bias factor $\left(B_{f}\right)$} & $\mathrm{RBF}$ & 0.9988 & 0.9434 & 0.9876 & 1.0005 & 1.0159 & 1.0030 \\
\hline & RSM & 1.0479 & 1.1211 & 1.0959 & 1.0384 & 0.7656 & 0.9604 \\
\hline \multirow[t]{2}{*}{ Accuracy factor $\left(A_{f}\right)$} & $\mathrm{RBF}$ & 1.0298 & 1.1616 & 1.0348 & 1.0389 & 1.0923 & 1.0496 \\
\hline & RSM & 1.3894 & 1.2362 & 1.3298 & 1.2113 & 1.6479 & 1.2870 \\
\hline \multirow[t]{2}{*}{ Portion of relative error ( $\mathrm{pRE}$ ) } & $\mathrm{RBF}$ & 0.9672 & 0.8125 & 0.9600 & 1.0000 & 0.9167 & 0.9829 \\
\hline & RSM & 0.5902 & 0.6250 & 0.5867 & 0.6947 & 0.6250 & 0.7009 \\
\hline
\end{tabular}


Fig. 3 Comparison of predicted and observed values of growth rate for Physisporinus vitreus (a-c) and Neolentinus lepideus (d-f) according to the radial basis function neural network $(\Delta)$ and the response surface model $(\circ)$ for the training, testing, and full data sets (a)

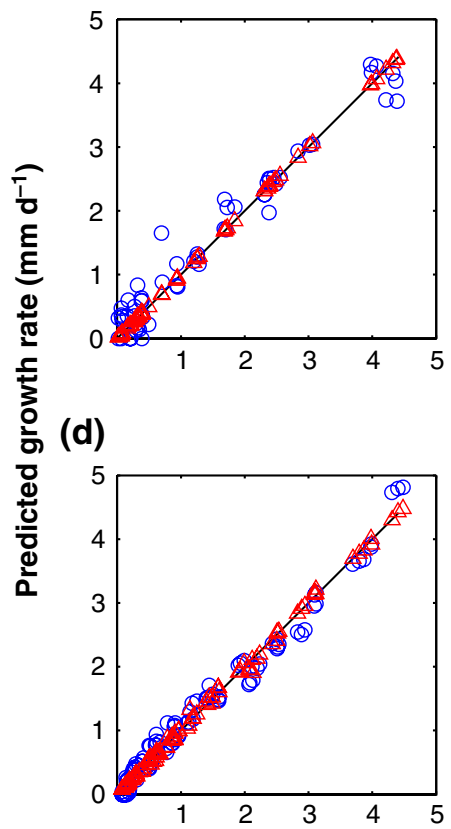

(b)

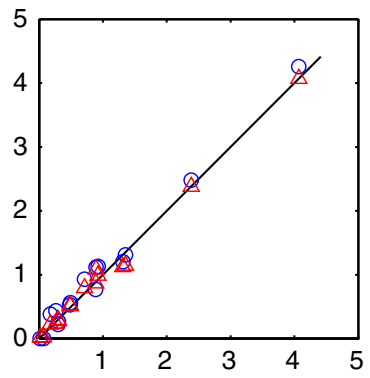

(e)

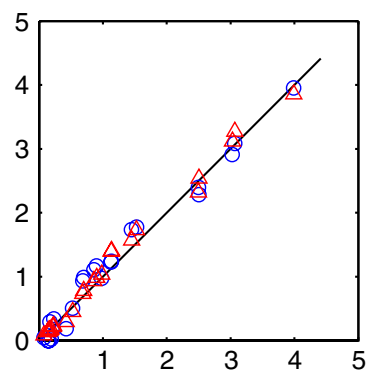

(c)

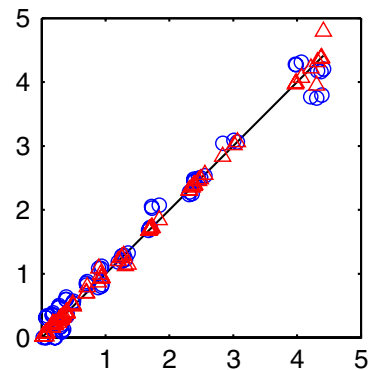

(f)

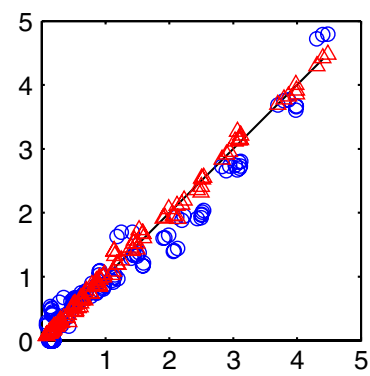

Observed growth rate $\left(\mathrm{mm} \mathrm{d}^{-1}\right)$

environmental conditions (Rayner and Boddy 1988), so for optimal use of these fungi in biotechnological processes it is necessary to broaden our knowledge of the influence of physical, physico-chemical, or chemical factors. In this study, two mathematical methods of prediction were compared to identify the effect of temperature, $a_{\mathrm{w}}$, and $\mathrm{pH}$ on the specific GRs of $P$. vitreus and $N$. lepideus. One approach was a classical method of statistical analysis, using RS methodology, and the other was based on ANN technology, using a RBF neural network.

Comparison of the two models was based on both graphical plots and evaluation indices (Table 1, Figs. 3, 4, and 5). The predictions of the generated quadratic polynomial model and of the RBF neural network correlated properly with the experimental observations, although the RBF neural network had better agreement for the training, testing, and full data sets for both fungi. The overall predictive capability of a model is commonly expressed by the coefficient of determination $\left(R^{2}\right)$, which measures how much of the variability of the observed response value is attributable to experimental factors and their interactions (Box and Draper 1987). In the present work, the calculated values of the coefficient were markedly high for all data sets of both fungi (RS model $>98 \%$; RBF $>99 \%$ ). However, the $R^{2}$ value alone is not a measure of a model's accuracy, because by adding a variable to the model the $R^{2}$ will increase, regardless of whether the additional variable is significant or not (Baş and Boyaci 2007). Thus, it is possible for models that have large values of $R^{2}$ to yield poor predictions of new observations or estimates of the mean response (Myers and Montgomery 1995). For this reason, further evaluation of the model's performance (verification) was quantified by calculating the RMSE, SEP\% (García-Gimeno et al. 2005; Zurera-Cosano et al. 2006), $A_{f}, B_{f}$ (Ross 1996), and pRE (Oscar 2005). RMSE provides a measure of the goodness-of-fit of a model to the data used to produce it (Box and Draper 1987). Table 1 shows the low values for RMSE for all data sets of $P$. vitreus and $N$. lepideus, which indicated a good fit of the experimental data by both models, although the RBF neural network showed in all cases lower values than the RS model. The index also provides information about how consistent the model would be in the long term (Lou and Nakai 2001).

The SEP index is the relative deviation of the mean prediction values and has the advantage of being independent of the magnitude of the measurements (García-Gimeno et al. 2005). Based on this index, the RBF neural network was far superior to the polynomial model for all data sets of both fungi (Table 1).

The MRPE and MAPE indices are similar to the bias $\left(B_{f}\right)$ and accuracy factors $\left(A_{f}\right)$ proposed by Ross (1996). Both indices, but MAPE in particular, indicated a better performance for the RBF neural network.

The prediction bias $\left(B_{f}\right)$ was calculated as described by Ross (1996), but the boundaries of the acceptable prediction zone were equivalent to those proposed by Ross et al. (2000) for unacceptable values of $B_{f}<0.70$ or $>1.15$. Because the $B_{f}$ value does not provide an indication of the average accuracy of the estimates, the $A_{f}$ was also calculated. Although a value 
Fig. 4 Comparison of residuals (predicted-observed growth rate) of Physisporinus vitreus (a, c, e) and Neolentinus lepideus $(\mathbf{b}, \mathbf{d}, \mathbf{f})$ according to the radial basis function neural network $(\Delta)$ and the response surface model $(\mathrm{O})$ for the training, testing, and full data sets (a)

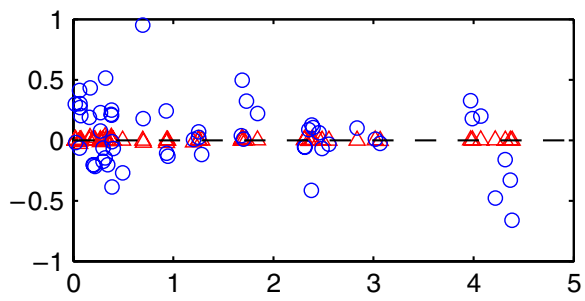

(c)

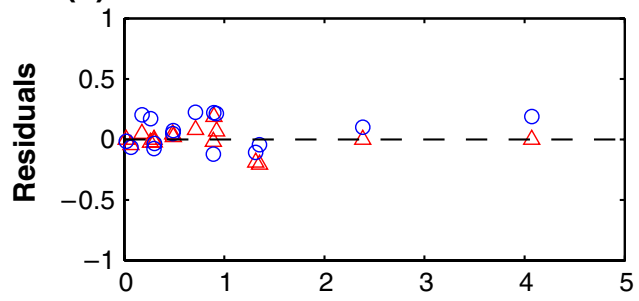

(e)

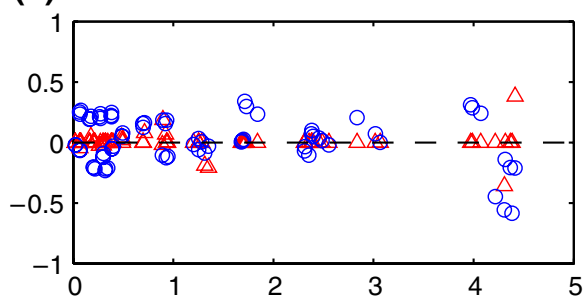

(b)

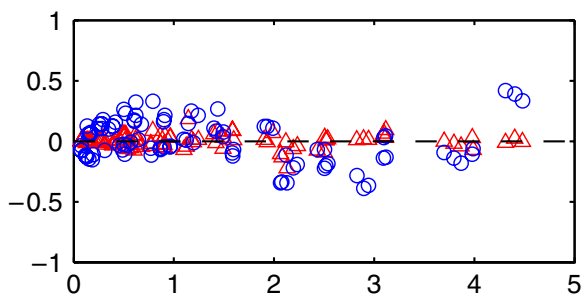

(d)

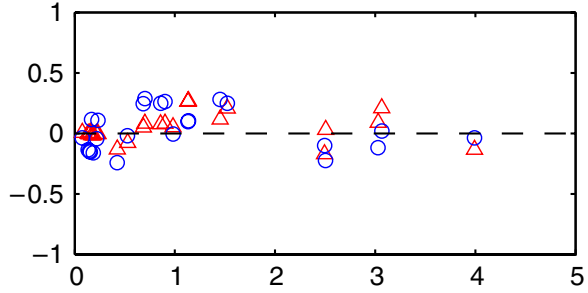

(f)

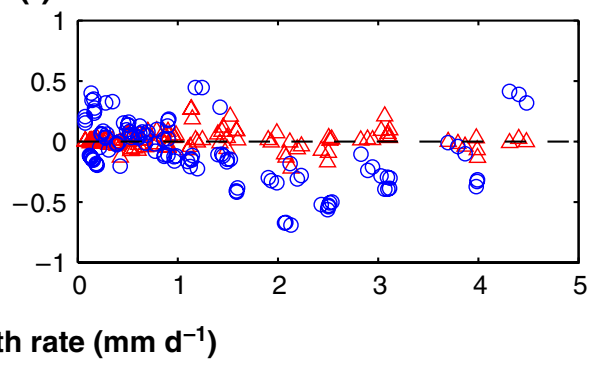

Fig. 5 Relative error (RE) plots with an acceptable prediction zone from RE -0.3 (fail-safe) to 0.15 (fail-dangerous) for comparison of observed and predicted values of specific growth rates of Physisporinus vitreus (a, c, e) and Neolentinus lepideus (b, d, f) according to the radial basis function neural network $(\Delta)$ and the response surface model ( $\mathrm{O}$ ) for the training, testing, and full data sets (a)

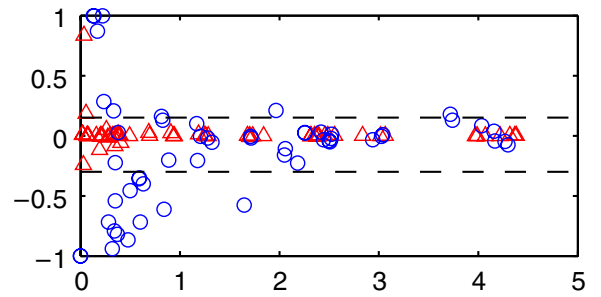

(c)

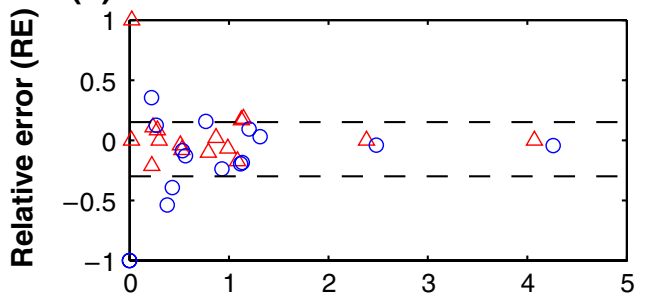

(e)

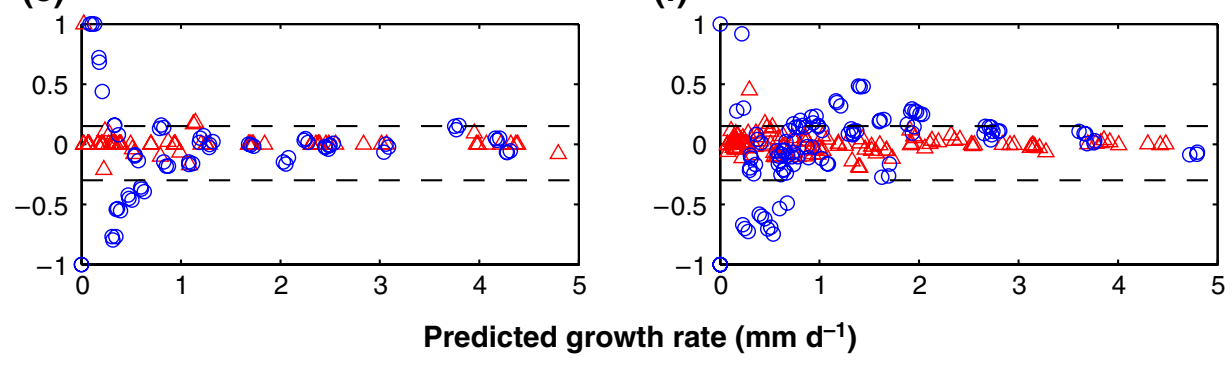

(b)

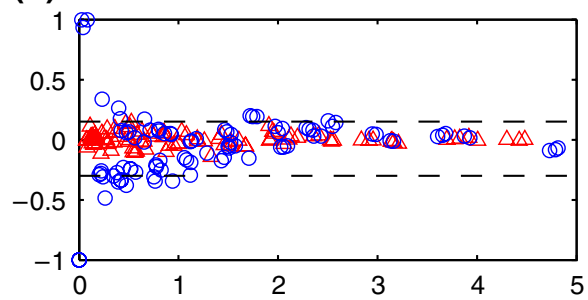

(d)

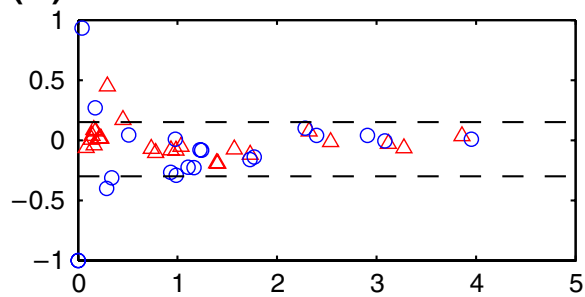

(f) 
Table 2 Model coefficients of the quadratic model and their significant effects on the radial growth rate $\left(\mathrm{mm} \mathrm{day}^{-1}\right)$ of Physisporinus vitreus and Neolentinus lepideus $a_{w}$ water activity, $T$ temperature

**Highly significant $(P<0.0001)$, * significant $(P<0.05),{ }^{\text {n.s. }}$ not significant $(P \geq 0.05)$

\begin{tabular}{|c|c|c|c|c|c|}
\hline \multirow[t]{2}{*}{ Coefficients } & & \multicolumn{2}{|c|}{ Data set of $P$. vitreus } & \multicolumn{2}{|c|}{ Data set of $N$. lepideus } \\
\hline & & Training & Full & Training & Full \\
\hline Intercept & $\beta_{0}$ & $1.4212 * *$ & $1.4461 * *$ & $1.2846^{* *}$ & $1.2427 * *$ \\
\hline$T$ & $\beta_{1}$ & $0.5571 * *$ & $0.5708 * *$ & $1.3165^{* *}$ & $1.2935^{* *}$ \\
\hline$a_{\mathrm{w}}$ & $\beta_{2}$ & $1.6250^{* *}$ & $1.6444^{* *}$ & $1.0523 * *$ & $1.0671^{* *}$ \\
\hline $\mathrm{pH}$ & $\beta_{3}$ & $0.0321 * *$ & $0.0059^{\mathrm{n} . \mathrm{s}}$ & $0.0079^{\mathrm{n} . \mathrm{s}}$ & $0.0125^{* *}$ \\
\hline$T^{2}$ & $\beta_{4}$ & $-0.5358 * *$ & $-0.6019^{* *}$ & $0.0518 * *$ & $0.0959 * *$ \\
\hline$a_{\mathrm{w}}^{2}$ & $\beta_{5}$ & $0.6848 * *$ & $0.7062 * *$ & $0.2417^{* *}$ & $0.2598^{* *}$ \\
\hline $\mathrm{pH}^{2}$ & $\beta_{6}$ & $-0.0270^{*}$ & $-0.0353^{*}$ & $-0.0541 * *$ & $-0.0422 * *$ \\
\hline$T \times a_{\mathrm{w}}$ & $\beta_{7}$ & $0.5080 * *$ & $0.5467 * *$ & $0.8674 * *$ & $0.8713 * *$ \\
\hline$T \times \mathrm{pH}$ & $\beta_{8}$ & $-0.0140^{\text {n.s. }}$ & $-0.0053^{\text {n.s. }}$ & $0.0104^{\text {n.s. }}$ & $-0.0004^{\text {n.s. }}$ \\
\hline$a_{\mathrm{w}} \times \mathrm{pH}$ & $\beta_{9}$ & $0.0559 * *$ & $0.0038^{\text {n.s. }}$ & $0.0125^{\text {n.s. }}$ & $0.0153^{*}$ \\
\hline
\end{tabular}

of 1 indicates that there is perfect consistency between all predicted and observed values, Ross et al. (2000) considered an $A_{f}$ value to be acceptable with an increase of up to 0.15 $(15 \%)$ for each variable included in the model. In the present case, the calculated $B_{f}$ and $A_{f}$ values for the RBF neural network and RS model, and for all data sets of both fungi, were in the defined acceptable range, which indicates high agreement, except for the RS model with the testing data set of $N$. lepideus, which revealed an unacceptable $A_{f}$ value of 1.6479 (Table 1).

However, these indices $\left(A_{f}, B_{f}\right)$ do not generate absolute measures of performance, because both are specific to the data sets used in the evaluation, so care should be taken with their interpretation (García-Gimeno et al. 2005). According to Dalgaard and Jørgensen (1998), a limitation of $A_{f}$ and $B_{f}$, which are ratios of the observed and predicted values, is that they cannot be calculated for cases in which no growth is predicted by the model and growth is observed or vice versa. In the present study, at suboptimal growth conditions, the RS model predicted no growth, but detectable growth occurred (data not shown). Excluding these cases leads to an overestimation of the model's performance, so it is recommended that for both indices $\left(A_{f}, B_{f}\right)$ there should be additional calculation of the $\mathrm{pRE}$ (Oscar 2005). For cases in which observed or predicted values are infinity or zero, the RE assigns a value of -1 for graphical presentation, which is an important feature of the acceptable prediction zone method because it allows the inclusion of no-growth cases in the calculation of the performance factor (Oscar 2005). In the present work, the boundaries of the acceptable prediction zone of the $\mathrm{pRE}$ were equivalent to those proposed by Ross et al. (2000), which are 0.7 (fail-safe) to 1.15 (fail-dangerous). Models with $\mathrm{pRE}>0.700$ are considered to provide prediction with acceptable bias and accuracy (Oscar 2005). The RBF neural network revealed for all data sets of both fungi acceptable values of $>0.700$, whereas the RS model revealed mostly unacceptable values of $<0.700$ (Table 1). The aforementioned remarks could explain this discrepancy of the indices and confirm the better performance of the RBF neural network compared with the statistical approach for modeling growth under in vitro conditions.

Predictive microbiology studies the behavior of microorganisms under different conditions and can help identify critical growth parameters, the most influential parameters, and thus the optimal cultivation/application conditions. In the present work, the selection of experimental conditions was based on the data of Schubert et al. (2009b), but included testing of a wider range of temperatures $\left(10-30^{\circ} \mathrm{C}\right)$ and more $a_{\mathrm{w}}$ values (nine) to observe the response of the
Table 3 Results of the sensitivity analysis ranking the parameters in order of importance for the growth rate $\left(\mathrm{mm} \mathrm{day}^{-1}\right)$ of Physisporinus vitreus and Neolentinus lepideus

\begin{tabular}{lllll}
\hline \multirow{2}{*}{ Fungus } & Data set & Parameters & & \\
\cline { 3 - 5 } & & Temperature $\left({ }^{\circ} \mathrm{C}\right)$ & Water activity $\left(a_{\mathrm{w}}\right)$ & $\mathrm{pH}$ \\
\hline P. vitreus & Training & 2 & 1 & 3 \\
& Testing & 2 & 1 & 3 \\
& Full & 2 & 1 & 3 \\
& Training & 1 & 2 & 3 \\
& Testing & 1 & 2 & 3 \\
& Full & 1 & 2 & 3 \\
\hline
\end{tabular}


fungi even under extreme environmental conditions. The sensitivity analysis of the RBF neural network and the multiple regression analysis confirmed the experimental results and showed that $a_{\mathrm{w}}$ is a particularly key determinant of the development of $P$. vitreus (Schmidt et al. 1996, 1997; Schubert et al. 2009b), whereas for $N$. lepideus temperature was the most influential parameter. The $\mathrm{pH}$ factor was the least important for both fungi, as the chosen experimental range of $\mathrm{pH}$ was found mainly in the optimum region for fungal growth. Both fungi showed their growth optimum under the highest $a_{\mathrm{w}}$ value (0.998) and at $\mathrm{pH} 5$, although $N$. lepideus revealed a relative tolerance to water stress. Griffin (1977) and Anagnost (2007) categorized most wood-decay fungi as hydrophilic organisms, which require $a_{\mathrm{w}} \geq 0.97$, but $N$. lepideus showed detectable growth at $a_{\mathrm{w}}=0.955$, provided the temperature was $>10{ }^{\circ} \mathrm{C}$. The most supportive temperature for $P$. vitreus was $20-25^{\circ} \mathrm{C}$ and at higher temperatures $\left(>25{ }^{\circ} \mathrm{C}\right)$, the GR declined. However, at all $a_{\mathrm{w}}$ levels, $N$. lepideus showed an increased GR with increasing temperature $\left(10-30{ }^{\circ} \mathrm{C}\right)$, but no final conclusion about its optimal growth temperature can be stated and further studies should include temperatures $>30{ }^{\circ} \mathrm{C}$.

The differences in the ecological demands of both fungi are expressed by their appearance on timber used in service. The strong dependence of $P$. vitreus on high moisture levels, its preferential colonization and degradation of watersaturated wood (wood moisture content WMC >100\%), even though fungal growth is normally impeded due to the lack of oxygen at WMC $>90 \%$, highlights the remarkable biological capacity of this fungus to degrade timber in the special habitat of cooling towers (Schmidt et al. 1996, 1997). $N$. lepideus showed an ability to sustain water stress in wood which coincides with its affinity to colonize creosoted railway sleepers, telegraph poles, and indoor timber, where ambient temperature is high and the relative humidity low (Cartwright and Findlay 1958; Rayner and Boddy 1988).

The results of this preliminary study demonstrate that modeling approaches, particularly the RBF neural network, combined with sensitivity analysis, represent a significant advance in defining the optimal environmental conditions for fast initial mycelial growth, which is important for the future optimization and success of biotechnological applications using $P$. vitreus and $N$. lepideus.

Acknowledgment The authors express their gratitude to the Swiss CTI (Innovation Promotion Agency) No. 8593.1 LSPP for its financial support.

\section{References}

Anagnost SE (2007) Wood in the built environment - conditions for mold and decay. In: Yang CS, Heinsohn P (eds) Sampling and analysis of indoor microorganisms. Wiley, Hoboken, pp 155-178
Baș D, Boyaci IH (2007) Modeling and optimization I: usability of response surface methodology. J Food Eng 78:836-845

Basheer IA, Hajmeer M (2000) Artificial neural networks: fundamentals, computing, design, and application. J Microbiol Methods 43:3-31

Begoude BAD, Lahlali R, Friel D, Tondje PR, Jijakli MH (2007) Response surface methodology study of the combined effects of temperature, $\mathrm{pH}$, and $\mathrm{a}_{\mathrm{w}}$ on the growth rate of Trichoderma asperellum. J Appl Microbiol 103:845-854

Box GEP, Draper NR (1987) Empirical model building and response surfaces. Wiley, New York

Carrasco E, García-Gimeno R, Seselovsky R, Valero A, Pérez F, Zurera G, Todd E (2006) Predictive model of Listeria monocytogenes' growth rate under different temperatures and acids. Food Sci Technol Int 12:47-56

Cartwright KSTG, Findlay WPK (1958) Decay of timber and its prevention, 2nd edn. HMSO, London

Cerniglia CE (1997) Fungal metabolism of polycyclic aromatic hydrocarbons: past, present and future applications in bioremediation. J Ind Microbiol Biotech 19:324-333

Dalgaard P, Jørgensen LV (1998) Predicted and observed growth of Listeria monocytogenes in seafood challenge tests and in naturally contaminated cold-smoked salmon. Int J Food Microbiol 40:105-115

Dallyn H, Fox A (1980) Spoilage of materials of reduced water activity by xerophilic fungi. In: Gould GH, Corry JEL (eds) Microbial growth in extremes of environment. Academic, San Diego, pp 129-139

Deflorio G, Hein S, Fink S, Spiecker H, Schwarze FWMR (2005) The application of wood decay fungi to enhance annual ring detection in three difuse-porous hardwoods. Dendrochronologia 22:123-130

Demuth H, Beale M, Hagan M (2008) Neural Network Toolbox ${ }^{\text {TM }} 6$ user's guide. MathWorks, Natick

Dong QL, Tu K, Guo LY, Hongwen LW, Zhao Y (2007) Response surface model for prediction of growth parameters from spores of Clostridium sporogenes under different experimental conditions. Food Microbiol 24:624-632

García-Gimeno RM, Barco E, Rincón F, Zurera-Cosano G (2005) Response surface model for the estimation of Escherichia coli O157: H7 growth under different experimental conditions. J Food Sci 70:M30-M36

Griffin DM (1977) Water potential and wood-decay fungi. Ann Rev Phytopathol 15:319-329

Hajmeer M, Basheer I, Cliver DO (2006) Survival curves of Listeria monocytogenes in chorizos modeled with artificial neural networks. Food Microbiol 23:561-570

Jeyamkondan S, Jayas DS, Holley RA (2001) Microbial growth modelling with artificial neural networks. Int J Food Microbiol 64:343-354

Lahlali R, Serrhini MN, Jijakli MH (2005) Studying and modelling the combined effect of temperature and water activity on the growth rate of $P$. expansum. Int J Food Microbiol 103:315-322

Lahlali R, Serrhini MN, Friel D, Jijakli MN (2006) In vitro effects of water activity, temperature and solutes on the growth rate of $P$. italicum Wehmer and $P$. digitatum Sacc. J Appl Microbiol 101:1198-1198

Lou W, Nakai S (2001) Artificial neural network-based predictive model for bacterial growth in a simulated medium of modifiedatmosphere-packed cooked meat products. J Agric Food Chem 49:1799-1804

Mai C, Kües U, Militz H (2004) Biotechnology in the wood industry. Appl Microbiol Biotechnol 63:477-494

Majcherczyk A, Hüttermann A (1988) Bioremediation of wood treated with preservative using white-rot fungi. In: Bruce A, Palfreyman JW (eds) Forest products biotechnology. Taylor and Francis, London, pp 129-140 
Messner K, Fackler K, Lamaipis P, Gindl W, Srebotnik E, Watanabe T (2002) Biotechnological wood modification. In: Proceedings of the International Symposium on Wood-based Materials, part 2. Vienna University, Vienna, pp 45-49

Myers RH, Montgomery DC (1995) Response surface methodology: process and product optimization using designed experiments. Wiley, New York

Noble PA, Almeida JS, Lovell CR (2000) Application of neural computing methods for interpreting phospholipid fatty acid profiles of natural microbial communities. Appl Environ Microbiol 66:694-699

Oscar TR (2005) Validation of lag time and growth rate models for Salmonella typhimurium: acceptable prediction zone method. J Food Sci 70:M129-M137

Panagou EZ, Kodogiannis VS (2009) Application of neural networks as a non-linear modelling technique in food mycology. Expert Syst Appl 36:121-131

Panagou EZ, Skandamis PN, Nychas GJE (2003) Modelling the combined effect of temperature, $\mathrm{pH}$ and $\mathrm{a}(\mathrm{w})$ on the growth rate of Monascus ruber, a heat-resistant fungus isolated from green table olives. J Appl Microbiol 94:146-156

Panagou EZ, Kodogiannis V, Nychas GJE (2007) Modelling fungal growth using radial basis function neural networks: the case of the ascomycetous fungus Monascus ruber van Tieghem. Int J Food Microbiol 117:276-286

Rayner ADM, Boddy L (1988) Fungal decomposition of wood: its biology and ecology. Wiley, Chichester

Richter DL, Warner JI, Stephens AL (2003) A comparison of mycorrhizal and saprotrophic fungus tolerance to creocote. Int Biodeterior Biodegrad 51:195-202

Ross T (1996) Indices for performance evaluation of predictive models in food microbiology. J Appl Bacteriol 81:501-508

Ross T, Dalgaard P, Tienungoon S (2000) Predictive modelling of the growth and survival of Listeria in fishery products. Int J Food Microbiol 62:231-245

Samson J, Langlois É, Lei J, Piché Y, Chênevert R (1998) Removal of 2, 4, 6-trinitrotoluene and 2, 4-dinitrotoluene by fungi (Ceratocystis coerulescens, Lentinus lepideus and Trichoderma harzianum). Biotechnol Lett 20:355-358

Schmidt O, Liese W, Moreth U (1996) Decay of timber in a water cooling tower by the basidiomycete Physisporinus vitreus. Mat Org 30:161-177
Schmidt O, Schmitt U, Moreth U, Potsch T (1997) Wood decay by the white-rotting basidiomycete Physisporinus vitreus from a cooling tower. Holzforschung 51:193-200

Schubert M, Mourad S, Fink S, Schwarze FWMR (2009a) Ecophysiological responses of the biocontrol agent Trichoderma atroviride (T-15603.1) to combined environmental parameters. Biol Control 49:84-90

Schubert M, Dengler V, Mourad S, Schwarze FWMR (2009b) Determination of optimal growth parameters for the bioincising fungus Physisporinus vitreus by means of response surface methodology. J Appl Microbiol 106:1734-1742

Schwarze FWMR (2008) Diagnosis and prognosis of the development of wood decay in urban trees. ENSPEC, Melbourne

Schwarze FWMR, Landmesser H (2000) Preferential degradation of pit membranes within tracheids by the basidiomycete Physisporinus vitreus. Holzforschung 54:461-462

Schwarze FWMR, Landmesser H, Zgraggen B, Heeb M (2006) Permeability changes in heartwood of Picea abies and Abies alba induced by incubation with Physisporinus vitreus. Holzforschung 60:450-454

Schwarze FWMR, Spycher M, Fink S (2008) Superior wood for violins - wood decay fungi as a substitute for cold climate. New Phytol 179:1095-1104

Shuen SK, Buswell JA (1992) Effect of lignin derived phenols and their methylated derivatives on the growth of Lentinus spp. Lett Appl Microbiol 15:12-14

Skinner GE, Larkin JW, Rhodehamel EJ (1994) Mathematical-modeling of microbial-growth: a review. J Food Safety 14:175-217

Sparringa RA, Kendall M, Westby A, Owens JD (2002) Effects of temperature, $\mathrm{pH}$, water activity and $\mathrm{CO}_{2}$ concentration on growth of Rhizopus oligosporus NRRL 2710. J Appl Microbiol 92:329-337

Spolaore P, Joannis-Cassan C, Duran E, Isambert A (2006) Optimization of Nannochloropsis oculata growth using the response surface method. J Chem Technol Biotechnol 81:1049-1056

Spycher M, Schwarze FWMR, Steiger R (2008) Assessment of resonance wood quality by comparing its physical and histological properties. Wood Sci Technol 42:325-342

Zurera-Cosano G, García-Gimeno RM, Rodríguez-Pérez R, HervásMartínez C (2006) Performance of response surface model for prediction of Leuconostoc mesenteroides growth parameters under different experimental conditions. Food Control 17:429438 